Article

\title{
Investigation on the Mechanical Properties of Mg-Al Alloys (AZ41 and AZ51) and Its Composites
}

Khin S. Tun ${ }^{1}{ }^{*}$, Ng J. Minh ${ }^{1}$, Quy B. Nguyen ${ }^{1}$, Abdel Magid Hamouda ${ }^{2}$ and Manoj Gupta $^{1}$

1 Department of Mechanical Engineering, National University of Singapore, 9 Engineering Drive 1, Singapore 117576, Singapore; E-Mails: ngjm87@gmail.com (N.J.M.); mpenqb@nus.edu.sg (Q.B.N.); mpegm@nus.edu.sg (M.G.)

2 Department of Mechanical and Industrial Engineering, College of Engineering, Qatar University, Doha 2713, Qatar; E-Mail: hamouda@qu.edu.qa

* Author to whom correspondence should be addressed; E-Mail: mpekst@nus.edu.sg; Tel.: +65-6516-8969; Fax: +65-6779-1459.

Received: 28 May 2012; in revised form: 10 July 2012 / Accepted: 17 August 2012 / Published: 29 August 2012

\begin{abstract}
In the present study, AZ41 and AZ51 alloys were fabricated using disintegrated melt deposition technique followed by hot extrusion. AZ41/Yttria and AZ51/Yttria composites were prepared using $0.6 \mathrm{wt} \%$ yttria nano particles in the alloys using the same fabrication technique. From the tensile test results, both strengths (yield and tensile) and ductility were improved in AZ51 when compared to AZ41. In comparison with its alloy counterparts, the yield and tensile strengths were enhanced while maintaining the same ductility in AZ41/Yttria composite, but comparable strengths with decreased ductility were observed in AZ51/Yttria composite. Under compressive loading, an improvement in strengths with similar ductility was observed in AZ51 when compared to AZ41. The best combination of strengths and ductility was observed in AZ51/Yttria composites from compression test results. The obtained mechanical properties are correlated with the microstructure observations.
\end{abstract}

Keywords: AZ31 magnesium alloy; yttria; microstructure; tensile; compression 


\section{Introduction}

Magnesium is the lightest structural metal with a potential to replace aluminum as its density is about 35\% lower than aluminum [1]. In its pure form, magnesium is not sufficiently strong to be used in many engineering applications. To improve its strength-to-weight ratio, magnesium is alloyed with various metals. Advantages such as high strength-to-density ratio, good machining ability, and weldability of magnesium alloys make them excellent candidates in both structural and nonstructural applications where the weight is of primary importance. Typical examples of magnesium alloys applications include steering wheels, gear box housing and seat frames in automobiles [2]. Based on different processing routes, magnesium alloys are divided into two groups: cast magnesium alloys and wrought magnesium alloys [3]. Among cast magnesium alloys, particularly AZ91 alloy systems were selected to be used in various structural components because of high specific strength and good castability [3-5]. Wrought magnesium alloys, having the advantage of better mechanical properties, can be used in some application areas such as window frames and seat frames. This opens up research interest in the development of new wrought magnesium alloys [6]. AZ31 is the most widely used wrought magnesium alloy because of its good combination of strength, ductility and corrosion resistance [3]. Consequently, diverse research efforts were made on AZ31 alloy systems to attain further improvements in mechanical properties [7-16]. Slip and twinning mechanisms of these alloys were investigated by using the modeling technique [7] and by performing compression tests [8]. Their deformation behaviors were also studied by using different techniques such as the equal-channel-angular-extrusion (ECAE) technique [9]. Considering the importance of $\mathrm{Mg}$ alloys' formability, investigations were made on mechanical anisotropy or tension-compression asymmetry [10,11]. In addition, the mechanical properties of AZ31 alloys under tension and compression were enhanced by using rare earth elements as alloying constituents [12], by adding reinforcements such as CNTs [13], nano ceramic particles [14,15] and ceramic + metal hybrid particles [16] into conventional AZ31 alloy.

In the present study, an attempt is made to investigate the properties of Al rich magnesium alloys, $\mathrm{AZ41}$ and $\mathrm{AZ51}$ and their composite counterparts containing nano $\mathrm{Y}_{2} \mathrm{O}_{3}$ particle reinforcements. The use of $\mathrm{Y}_{2} \mathrm{O}_{3}$ in pure $\mathrm{Mg}$ leads to improvement in tensile properties [17-19]. In the current paper, we investigate the effect of $\mathrm{Y}_{2} \mathrm{O}_{3}$ addition on the variation in mechanical properties of $\mathrm{Mg}$ alloys. The materials were synthesized using the Disintegrated Melt Deposition (DMD) technique followed by hot extrusion. Particular emphasis was placed on correlating the microstructure evolution and mechanical properties of the synthesized materials. Analyses were done on microstructure, microhardness, tensile and compressive properties.

\section{Results and Discussion}

\subsection{Microstructure}

The grain size variation in the synthesized materials can be seen in Table 1 and Figure 1 . The results showed that the average grain size in AZ51 alloy is about half when compared to AZ41 alloy. In case of their composites counterparts containing $\mathrm{Y}_{2} \mathrm{O}_{3}$ reinforcement, grain size reduction was noticeable in $\mathrm{AZ41}+\mathrm{Y}_{2} \mathrm{O}_{3}$ composite when compared to AZ41, whereas the grains of $\mathrm{AZ51}+\mathrm{Y}_{2} \mathrm{O}_{3}$ 
composite were coarser when compared to AZ51. The results indicate that the addition of either $\mathrm{Al}$ or $\mathrm{Y}_{2} \mathrm{O}_{3}$ into AZ41 has the ability to reduce the grain size. In $\mathrm{Mg}$-Al alloy systems, the formation of $\mathrm{Mg}_{17} \mathrm{Al}_{12}$ is commonly observed [20]. When compared to AZ41 (AZ31 + 1Al), the formation of a larger amount of $\mathrm{Mg}_{17} \mathrm{Al}_{12}$ was observed in $\mathrm{AZ51}(\mathrm{AZ31}+2 \mathrm{Al})$ due to the increased addition of $\mathrm{Al}$ into AZ31 (Figure 1a,c). The $\mathrm{Mg}_{17} \mathrm{Al}_{12}$ intermetallics formed in AZ51 were seen as the fine phases (Figures 1c,2c). In AZ51 alloy, the grain size reduction can be attributed to the coupled effects of (a) the increased content of $\mathrm{Al}$ addition and the presence of fine $\mathrm{Mg}_{17} \mathrm{Al}_{12}$ intermetallics. It has been reported that the grain refinement in $\mathrm{Mg}$ - $\mathrm{Al}$ system ( $\mathrm{Al}$ content above $1 \mathrm{wt}$ pct.) is mainly due to superheating process. Ideally for $\mathrm{Mg}$ alloys with high $\mathrm{Al}$ content, the grain refinement readily occurs by superheating $[21,22]$. In the present study, the materials were processed at a superheated temperature of $750{ }^{\circ} \mathrm{C}$. Accordingly the grain refinement is favored in AZ51 with increased Al content when compared to AZ41. In addition, the presence of fine intermetallics can act as the nucleation sites or restrict the grain growth during solidification which is supported by the microstructural evidences revealing the finely dispersed intermetallics and their location at grain boundaries in AZ51 (Figure 1c). For $\mathrm{AZ41}+\mathrm{Y}_{2} \mathrm{O}_{3}$ composite, the combined presence of fine intermetallic phase and the $\mathrm{Y}_{2} \mathrm{O}_{3}$ reinforcements may be attributed to grain refinement. In the case of AZ51, fine intermetallics could have contributed in refining the grain size. Having very fine particle size $(<1 \mu \mathrm{m})$, there is less possibility for $\mathrm{Y}_{2} \mathrm{O}_{3}$ to serve as nucleation sites [23] but as obstacles for grain growth. The presence of $\mathrm{Y}_{2} \mathrm{O}_{3}$ together with fine intermetallics assisted in restricting the grain growth. In the case of $\mathrm{AZ51}+\mathrm{Y}_{2} \mathrm{O}_{3}$ composite, however, the addition of $\mathrm{Y}_{2} \mathrm{O}_{3}$ seems to have null effect on grain refinement (Table 1). As can be seen in the microstructure (Figures $1 \mathrm{~d}$ and $2 \mathrm{~g}$ ), $\mathrm{Y}_{2} \mathrm{O}_{3}$ particles are individually present at the grain boundary and within the grains in the composite. However there is insufficient restriction ability of fine and individual nano particles to refine the grains. This is in agreement with the previous finding which indicated that a sufficient amount of nano particles at the grain boundary is needed for effective grain refinement [24]. Moreover, the addition of $\mathrm{Y}_{2} \mathrm{O}_{3}$ can have a different effect on the grain refinement of $\mathrm{Mg}$-Al alloys depending on the different $\mathrm{Al}$ content. In an earlier report [23], the alloying element $(\mathrm{Sr})$ and reinforcement particle $(\mathrm{SiC})$ have significant grain refinement effect in low $\mathrm{Al}$ containing alloy but refining efficiency decreases with the increase of $\mathrm{Al}$ content.

Table 1. Results of grain size and microhardness.

\begin{tabular}{lcc}
\hline Materials & Grain size $(\boldsymbol{\mu m})$ & Microhardness $(\mathbf{H V})$ \\
\hline $\mathrm{AZ41}$ & $3.8 \pm 1.6$ & $69 \pm 2$ \\
$\mathrm{AZ51}$ & $2.0 \pm 0.9$ & $79 \pm 1$ \\
$\mathrm{AZ41}+\mathrm{Y}_{2} \mathrm{O}_{3}$ & $2.4 \pm 1.1$ & $82 \pm 2$ \\
$\mathrm{AZ51}+\mathrm{Y}_{2} \mathrm{O}_{3}$ & $3.6 \pm 1.7$ & $73 \pm 1$ \\
\hline
\end{tabular}


Figure 1. Field Emission Scanning Electron Microscope (FESEM) micrographs showing the grain size and second phase distribution in: (a) AZ41; (b) $\mathrm{AZ41}+\mathrm{Y}_{2} \mathrm{O}_{3}$; (c) AZ51; (d) $\mathrm{AZ51}+\mathrm{Y}_{2} \mathrm{O}_{3}$.

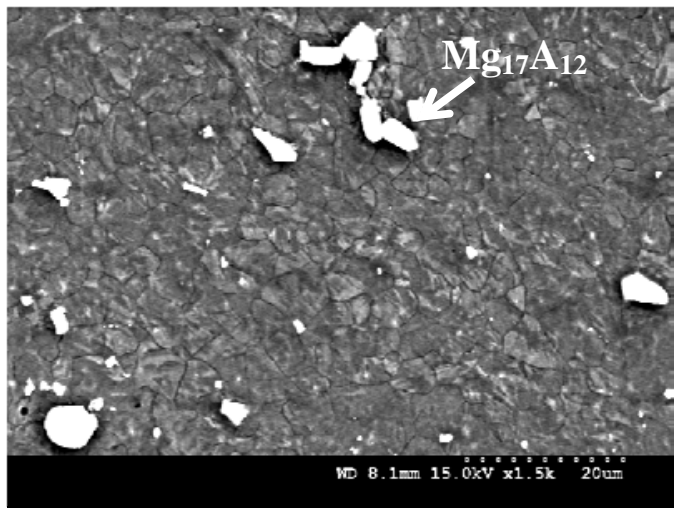

(a)

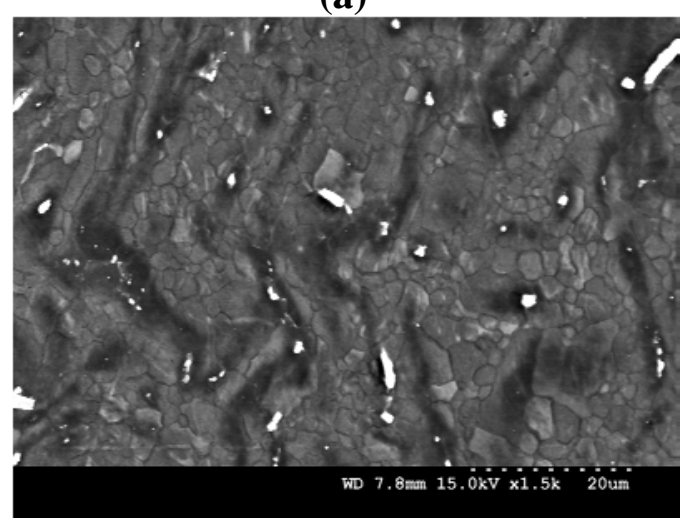

(c)

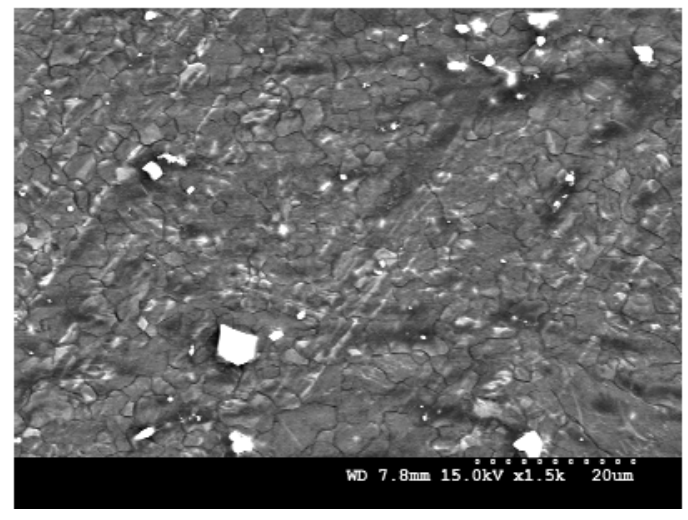

(b)

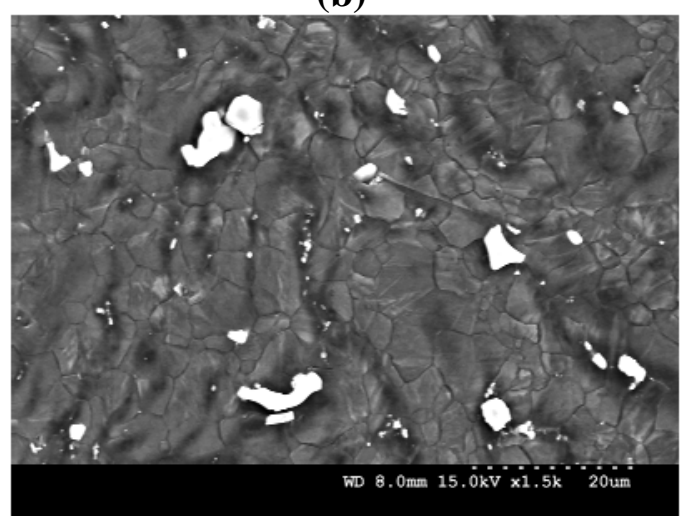

(d)

The second phase distribution in the synthesized materials is shown in Figure 2. Similar microstructure with the presence of coarse intermetallics in blocky-shape was observed in AZ41 and AZ51 $+\mathrm{Y}_{2} \mathrm{O}_{3}$ composite (Figure 2a,d). In case of AZ41 $+\mathrm{Y}_{2} \mathrm{O}_{3}$ composite, some of the coarse intermetallics broke up into fine intermetallics as can be seen in the microstructure (Figures $1 \mathrm{~b}$ and $2 \mathrm{~b}$ ). In the related studies [25,26], the continuous network of $\mathrm{Mg}_{17} \mathrm{Al}_{12}$ intermetallic phase in AZ91D alloy was modified into discontinuous form revealing finer intermetallic phase in their composites containing $\mathrm{TiB}_{2}$ and $\mathrm{Al}_{2} \mathrm{O}_{3}$ nano particles. Also in the previous study [14], Nguyen and Gupta reported the break-down of coarse $\mathrm{Mg}_{17} \mathrm{Al}_{12}$ intermetallic phase in $\mathrm{AZ} 31 \mathrm{~B} / \mathrm{Al}_{2} \mathrm{O}_{3}$ nanocomposite. These results clearly showed that the addition of nanoparticles into Mg-Al alloys can assist in the modification of existing intermetallic morphology in their related $\mathrm{Mg}$-Al alloy matrices. In the present study, the use of $\mathrm{Y}_{2} \mathrm{O}_{3}$ nanoparticles provides the same ability to refine the coarse intermetallic compound as observed in the resultant microstructure of $\mathrm{AZ41}+\mathrm{Y}_{2} \mathrm{O}_{3}$ composite (Figures $1 \mathrm{~b}$ and $2 \mathrm{~b}$ ). In case of AZ51, the formation of fine, needle-shape intermetallics besides coarse, blocky intermetallics were observed in the microstructure (Figure 2c,e). From the investigation on Mg-Al-RE alloy [27], it was reported that the addition of misch metal (rare earth element, RE) into AZ91 alloy causes the formation of rod like Al-RE intermetallics among eutectic $\mathrm{Mg}_{17} \mathrm{Al}_{12}$ intermetallic phase. The same phenomena could happen in the AZ51 alloy and the change in intermetallic morphology might be attributed to the addition of $2 \mathrm{wt} \% \mathrm{Al}$ into $\mathrm{AZ31}$. In contrast to $\mathrm{AZ41} / \mathrm{Y}_{2} \mathrm{O}_{3}$ composite, the addition of $\mathrm{Y}_{2} \mathrm{O}_{3}$ nanoparticle was 
unable to break down the coarse intermetallics in $\mathrm{AZ51} / \mathrm{Y}_{2} \mathrm{O}_{3}$ composite which revealed only coarse, blocky intermetallics in the microstructure (Figures $1 \mathrm{~d}$ and $2 \mathrm{~d}$ ). It may be attributed to the increased formation of intermetallics which is beyond the critical amount which suppress the ability of $\mathrm{Y}_{2} \mathrm{O}_{3}$ to support the breakdown of these intermetallics. In addition, fine, needle-shape intermetallics which were previously observed in AZ51 alloy were not found in its composite (see Figure 2d). However, the exact phenomenon causing the coarsening of the original fine intermetallics formation due to the presence of $\mathrm{Y}_{2} \mathrm{O}_{3}$ in this particular composite is not clear and further investigation is needed.

Figure 2. FESEM micrographs showing second phase morphology and distribution in: (a) AZ41; (b) AZ41 $+\mathrm{Y}_{2} \mathrm{O}_{3}$ composite; (c) AZ51 and (d) AZ51 $+\mathrm{Y}_{2} \mathrm{O}_{3}$ composite; (e) EDS (Energy-dispersive $\mathrm{X}$-ray Spectroscopy) analysis on the needle-shaped intermetallic; the presence of individual $\mathrm{Y}_{2} \mathrm{O}_{3}$ reinforcement in (f) $\mathrm{AZ} 41 / \mathrm{Y}_{2} \mathrm{O}_{3}$ composite; and (g) $\mathrm{AZ} 51 / \mathrm{Y}_{2} \mathrm{O}_{3}$ composite.

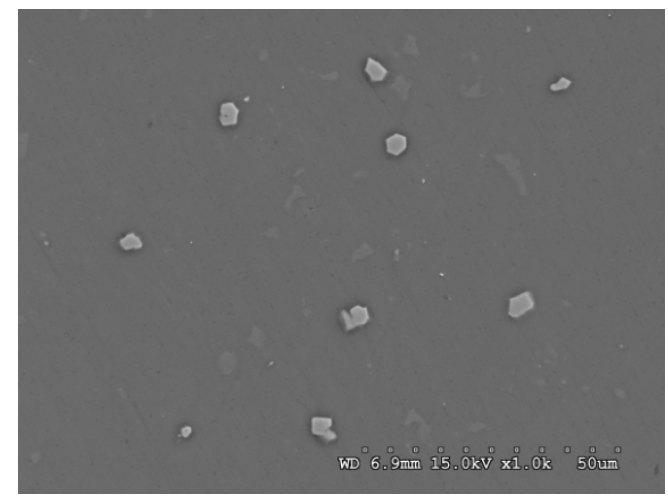

(a)

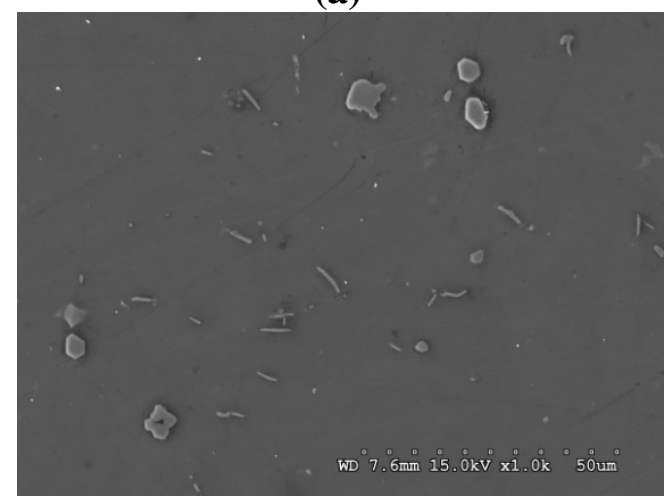

(c)

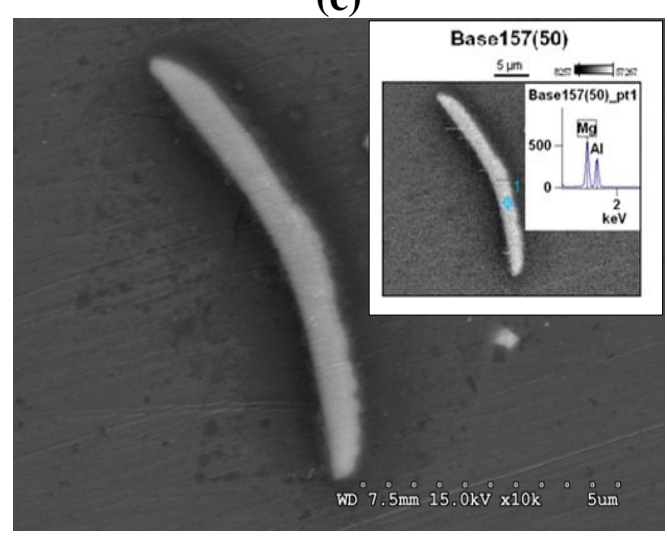

(e)

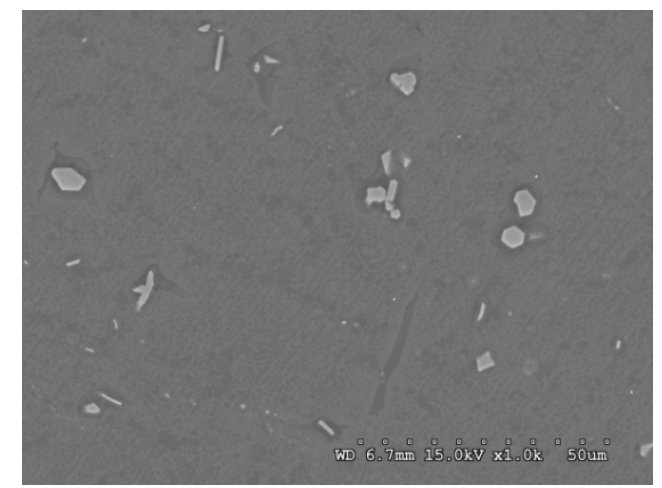

(b)

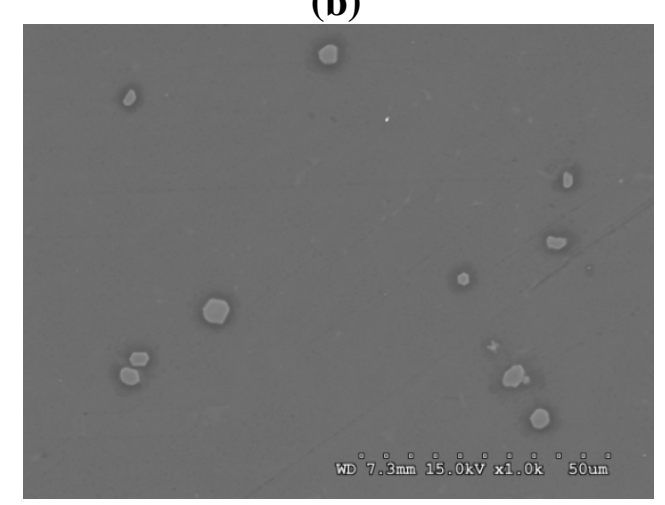

(d)

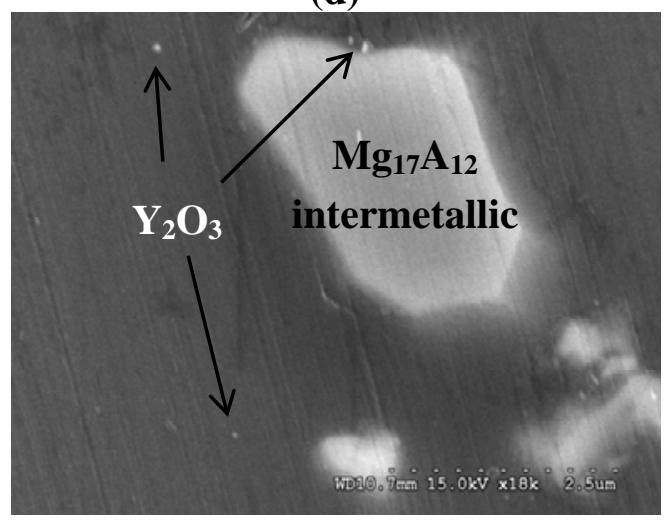

(f) 
Figure 2. Cont.

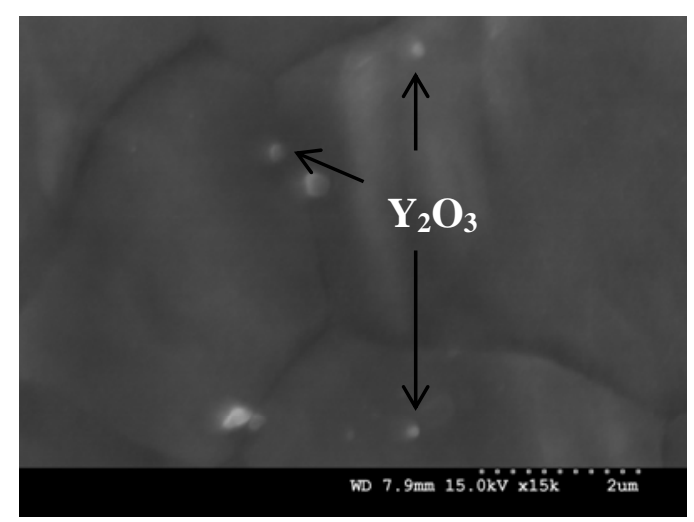

(g)

\subsection{XRD Analysis}

Figure 3 shows the results of X-ray diffraction analysis on the synthesized materials. As seen in the figure, the peak related to $\mathrm{Mg}_{17} \mathrm{Al}_{12}$ intermetallics was detected with a very low intensity in $\mathrm{AZ} 41$ and $\mathrm{AZ51} / \mathrm{Y}_{2} \mathrm{O}_{3}$ composite whereas no such peak was detected in AZ51 and AZ41/ $\mathrm{Y}_{2} \mathrm{O}_{3}$ composite. In the composite samples, $\mathrm{Y}_{2} \mathrm{O}_{3}$ phase was not detected in the XRD profile. In most of the $\mathrm{Mg}-\mathrm{Al}$ alloy systems, the $\mathrm{Mg}_{17} \mathrm{Al}_{12}$ intermetallic phases are commonly found in the form of continuous network [20]. In the present study, from the microstructure, the $\mathrm{Mg}_{17} \mathrm{Al}_{12}$ intermetallic phases were seen as discontinuous phases like reinforcements in all synthesized materials which are uniformly distributed in the matrix and it was confirmed by EDS (Energy-dispersive X-ray Spectroscopy) analysis (Figure 2e). The presence of larger size intermetallics in $\mathrm{AZ41}$ and $\mathrm{AZ51} / \mathrm{Y}_{2} \mathrm{O}_{3}$ composite can be correlated to the observation of low intensity peak matched to $\mathrm{Mg}_{17} \mathrm{Al}_{12}$ phase. The absence of $\mathrm{Y}_{2} \mathrm{O}_{3}$ and $\mathrm{Mg}_{17} \mathrm{Al}_{12}$ intermetallic peaks in $\mathrm{AZ51}$ and $\mathrm{AZ41} / \mathrm{Y}_{2} \mathrm{O}_{3}$ composite can be attributed to the fine particulate/intermetallic size as observed in their microstructures. From the related studies [19], the peaks related to the ceramic reinforcement particles which are in nano length scale do not generally appear in the composites. This is due to either the amount of reinforcement used was quite small (less than 2 vol.\%) to be detected due to the limitation of current XRD diffractrometer or the presence of fine particles/second phases which are individually or uniformly distributed with small clusters in the matrix [28,29].

XRD studies were also conducted in both transverse (perpendicular to the extrusion/loading axis) and longitudinal (parallel to the extrusion/loading axis) directions (Figure 4) to analyze the crystal orientation, particularly the basal plane orientation. Only in the case of AZ51, the peak related to the basal plane was observed in both transverse and longitudinal XRD patterns which can be mentioned as random texture (Figure 4b). This indicates that in AZ51 there is no strong basal texture in which basal peak appears only in the longitudinal scan. In $\mathrm{AZ41} / \mathrm{Y}_{2} \mathrm{O}_{3}$ composite, the basal peak was almost absent in the transverse scan (Figures 3 and $4 \mathrm{a}$ ) but the strong basal peak was observed in the longitudinal scan (Figure 4a) showing stronger basal texture when compared to AZ51. The similar basal texture as in the case of $\mathrm{AZ} 41 / \mathrm{Y}_{2} \mathrm{O}_{3}$ composite was observed in the rest of the synthesized materials. 
Figure 3. X-ray diffractograms of the synthesized materials.

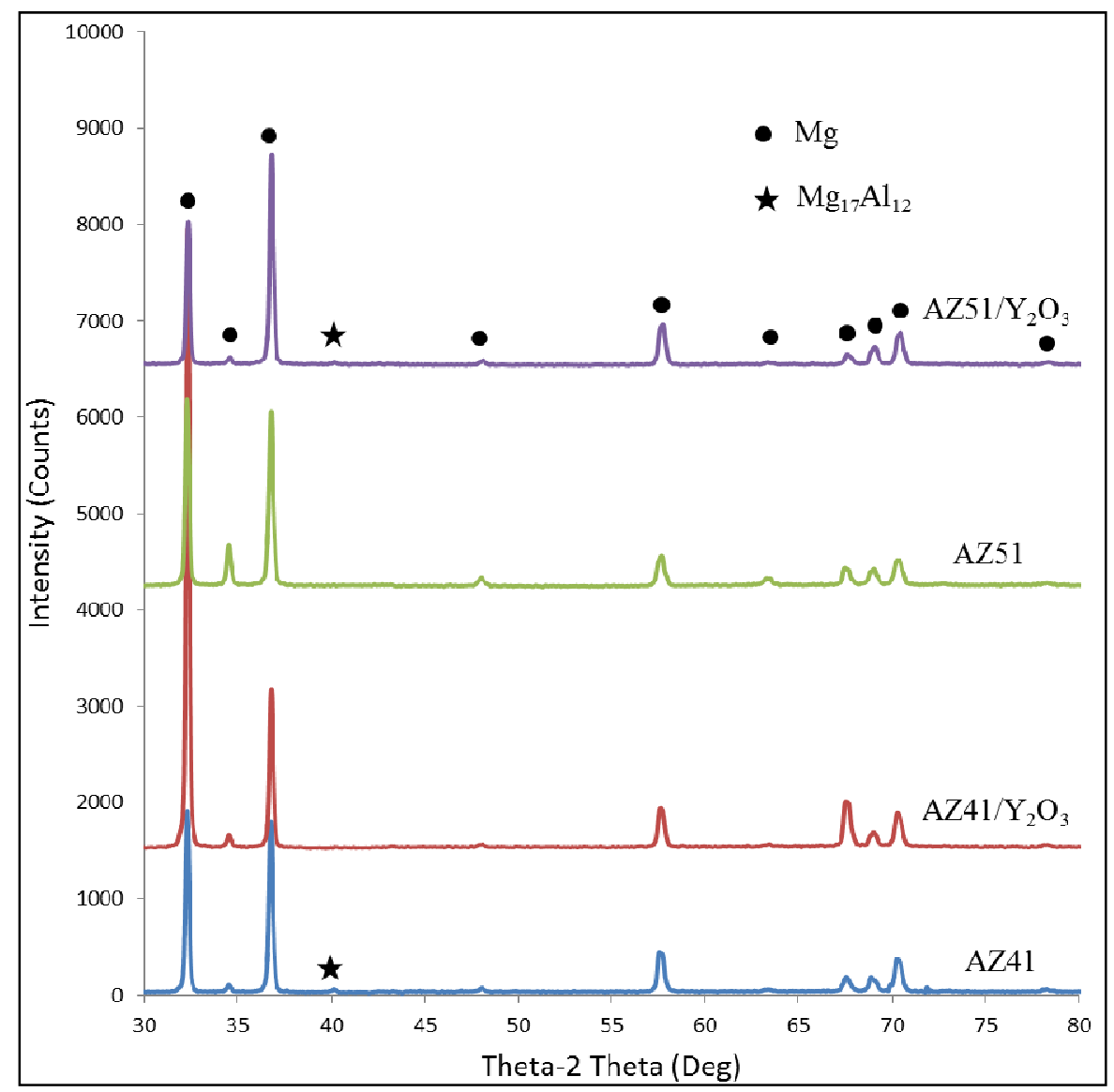

Figure 4. X-ray diffractograms showing basal (0002) plane distribution in: (a) $\mathrm{AZ} 41 / \mathrm{Y}_{2} \mathrm{O}_{3}$; (b) AZ51.

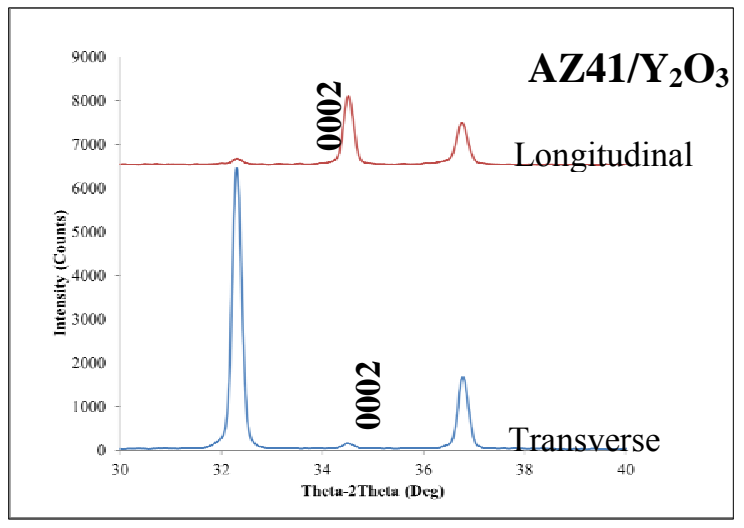

(a)

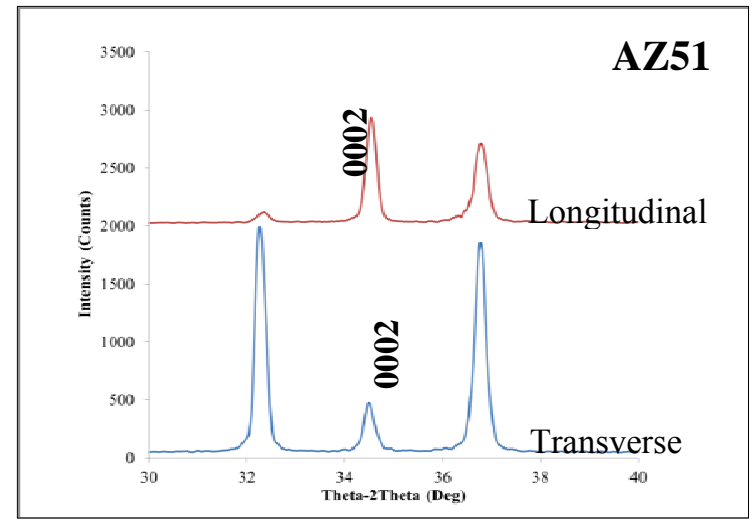

(b)

\subsection{Microhardness}

The results of hardness measurements are shown in Table 1. A significant improvement in microhardness was observed in $\mathrm{AZ} 41 / \mathrm{Y}_{2} \mathrm{O}_{3}$ composite when compared to its unreinforced counterpart, AZ41. Similarly, an increment in microhardness was observed with the higher percentage of alloying element in AZ51 (AZ31 + 2Al) when compared to AZ41 (AZ31 + 1Al). The hardness improvement in 
$\mathrm{AZ41} / \mathrm{Y}_{2} \mathrm{O}_{3}$ composite and AZ51 can be attributed to: (a) the reduction in grain size; (b) the increasing amount of uniformly distributed second phases; and (c) the presence of fine reinforcement particles and/or fine intermetallics. To improve the matrix microhardness, sufficiently large amounts of second phases as well as their uniform distribution is required. In case of $A Z 51 / \mathrm{Y}_{2} \mathrm{O}_{3}$ composite, a marginal increment in microhardness when compared to AZ41 but its hardness value was decreased when compared to $\mathrm{AZ41} / \mathrm{Y}_{2} \mathrm{O}_{3}$ composite and AZ51 (see Table 1). As observed in the microstructure (Figure 2a,d), the presence of coarse intermetallic formation was found in $A Z 51 / \mathrm{Y}_{2} \mathrm{O}_{3}$ composite which is similar to that of AZ41. The intermetallic distribution in both AZ41 and $A Z 51 / \mathrm{Y}_{2} \mathrm{O}_{3}$ composite were uniform but the interparticle distance was larger between coarse intermetallics. This led to the reduced matrix hardness of $A Z 51 / \mathrm{Y}_{2} \mathrm{O}_{3}$ composite when compared to $\mathrm{AZ} 41 / \mathrm{Y}_{2} \mathrm{O}_{3}$ composite and AZ51 where the matrix deformation was effectively constrained by the closely spaced fine intermetallics (Figure 2b,c). A marginally higher hardness in $\mathrm{AZ51} / \mathrm{Y}_{2} \mathrm{O}_{3}$ composite than that in $\mathrm{AZ41}$ can be attributed to the presence of $\mathrm{Y}_{2} \mathrm{O}_{3}$ particles in the matrix. With addition of $\mathrm{Y}_{2} \mathrm{O}_{3}$ into the alloys, AZ41 and AZ51, grain refinement and fine intermetallic formation led to the improved microhardness in $\mathrm{AZ41} / \mathrm{Y}_{2} \mathrm{O}_{3}$ composite whereas grain and intermetallic coarsening led to the reduction of microhardness inAZ51/ $\mathrm{Y}_{2} \mathrm{O}_{3}$ composite.

\subsection{Tensile Properties}

The tensile test results of the synthesized materials are shown in Table 2. From the results, a significant improvement in $0.2 \%$ yield strength and ultimate tensile strength of AZ41 alloy was observed with the use of $\mathrm{Y}_{2} \mathrm{O}_{3}$ as reinforcement. On the other hand, considering the standard deviation, the similar strength level was observed between AZ51 and $A Z 51 / \mathrm{Y}_{2} \mathrm{O}_{3}$ composite. When compared to AZ41, both $0.2 \%$ yield strength and ultimate tensile strength were increased in AZ51. The strengths improvement in $\mathrm{AZ41} / \mathrm{Y}_{2} \mathrm{O}_{3}$ and AZ51 can commonly be attributed to: (a) grain size strengthening due to grain refinement through well-known Hall-Petch relationship and (b) effective load transfer from matrix to second phases. The presence of increased but fine and uniformly distributed second phases can act as the additional barriers for dislocation initiation and subsequently retard the dislocation movement. This can contribute to the need of higher tensile load translating to the improved yield and tensile strengths. Among all the synthesized materials, $\mathrm{AZ} 41 / \mathrm{Y}_{2} \mathrm{O}_{3}$ composite showed the best $0.2 \%$ yield strength and ultimate tensile strength. This indicates that there was additional strengthening from $\mathrm{Y}_{2} \mathrm{O}_{3}$ reinforcement in $\mathrm{AZ} 41 / \mathrm{Y}_{2} \mathrm{O}_{3}$ composite. The additional contributing factors due to the presence of $\mathrm{Y}_{2} \mathrm{O}_{3}$ reinforcement in composite strength increment could be: (a) Orowan strengthening due to the presence of nano particle reinforcement (Figure 2f); and (b) elastic and CTE (Coefficient of Thermal Expansion) mismatch between $\mathrm{Mg}$ matrix and $\mathrm{Y}_{2} \mathrm{O}_{3}$ reinforcement [18,19].

Table 2. Results of room temperature tensile properties.

\begin{tabular}{lccc}
\hline Materials & 0.2\% YS (MPa) & UTS (MPa) & Failure strain (\%) \\
\hline $\mathrm{AZ41}$ & $184 \pm 4$ & $283 \pm 4$ & $13 \pm 2$ \\
$\mathrm{AZ51}$ & $204 \pm 4$ & $300 \pm 5$ & $18 \pm 2$ \\
$\mathrm{AZ41}+\mathrm{Y}_{2} \mathrm{O}_{3}$ & $230 \pm 2$ & $311 \pm 2$ & $13 \pm 2$ \\
$\mathrm{AZ} 51+\mathrm{Y}_{2} \mathrm{O}_{3}$ & $190 \pm 4$ & $295 \pm 2$ & $12 \pm 1$ \\
\hline
\end{tabular}


Having coarser grains and lack of fine intermetallic formation compared to AZ51, it is reasonable that the strengths were not improved in $A Z 51 / \mathrm{Y}_{2} \mathrm{O}_{3}$ composite. With these drawbacks from the microstructure aspect, the strengthening effect from $\mathrm{Y}_{2} \mathrm{O}_{3}$ reinforcement could not sufficiently provide higher strength in the composite. Although the strengths were not improved when compared to AZ51, both $0.2 \%$ yield strength and ultimate tensile strength in $A Z 51 / \mathrm{Y}_{2} \mathrm{O}_{3}$ composite were found to be higher than that of $A Z 41$. In $A Z 41$ and $A Z 51 / \mathrm{Y}_{2} \mathrm{O}_{3}$ composite, similar microstructural coarsening (grain size, intermetallic size and distribution) was seen from the microstructure observation (Figure 1a,d and Figure 2a,d). This indicates that the combined strengthening effect from increased amount of intermetallics and $\mathrm{Y}_{2} \mathrm{O}_{3}$ reinforcement could contribute to the strength improvement of $\mathrm{AZ51} / \mathrm{Y}_{2} \mathrm{O}_{3}$ composite.

In all synthesized materials, the failure strain level was found to be the same except that for AZ51. Based on the earlier studies [9,14,17-19,30,31], the ductility improvement in magnesium materials can be due to the presence of fine particles, non-basal slip activation, grain refinement and texture changes. The presence of $\mathrm{Y}_{2} \mathrm{O}_{3}$ nano particles has shown the ability to improve ductility of pure $\mathrm{Mg}$ in the previous studies [17-19] by activating cross slip and/or non-basal slip. In the present study, the improvement in failure strain was not observed in the composites through the addition of $\mathrm{Y}_{2} \mathrm{O}_{3}$ into $\mathrm{Mg}$ alloy matrices (Table 2). Although $\mathrm{Y}_{2} \mathrm{O}_{3}$ was present in AZ41, the same failure strain was maintained in the composite counterpart. In case of $A Z 51 / \mathrm{Y}_{2} \mathrm{O}_{3}$ composite, the failure strain was reduced when compared to AZ51. The results clearly indicate that the effect of $\mathrm{Y}_{2} \mathrm{O}_{3}$ on the ductility improvement was influenced by the existence of intermetallics in the $\mathrm{Mg}$ alloy matrices. It is more obvious in the case of $\mathrm{AZ51} / \mathrm{Y}_{2} \mathrm{O}_{3}$ composite in which the coarse intermetallics formation is mainly responsible for the reduction in failure strain. It is well known that the creation of fine $\mathrm{Mg}_{17} \mathrm{Al}_{12}$ phase or reducing the amount of this phase in the related alloy systems is one way to overcome the deterioration of ductility in Mg-Al alloys [20]. It has been shown that there is the generation of geometrically necessary dislocations in the materials such as composites and alloys which are plastically inhomogeneous $[32,33]$. According to the prismatic punching model proposed by Arsenault and Shi [33], higher theoretical dislocation density was found in the composite containing whiskers when compared to platelets and particle reinforced composites. This model is also applicable to the alloys containing second phase precipitates. Following the above model, Goh et al. [31] investigated the generation of dislocations in $\mathrm{Mg} / \mathrm{CNT}$ composite using TEM study. It was reported that the generation of more dislocations of $<\mathrm{a}>$ and $<\mathrm{c}+\mathrm{a}>$ types due to the presence of CNTs induces the activation of non-basal and cross slip in the composite which resulted in the improvement in ductility. In the present study, the formation on needle shaped intermetallics can induce the generation of geometrically necessary dislocation in AZ51 [32] as in the case of CNT reinforced composite. Consequently, the activation of more slip systems besides basal slip is expected for the failure strain improvement in AZ51. As reported in the previous studies [14,17], having grain refinement in magnesium materials is one of the reasons for ductility improvement. In the present investigation, the ductility improvement was only observed in AZ51 although grain refinement was attained in both AZ51 and $A Z 41 / \mathrm{Y}_{2} \mathrm{O}_{3}$ composite. Under the condition of having similar grain size, the texture changes can be accounted for by the variation in ductility [9,31]. From the XRD patterns shown in Figure 4, the existence of random basal texture was observed in AZ51 composite whereas a comparatively stronger basal texture was observed $\mathrm{AZ41} / \mathrm{Y}_{2} \mathrm{O}_{3}$ composite. Random basal texture showing basal peak in both 
transverse and longitudinal direction implies the deviation of some basal plane orientation from being aligned with the extrusion axis (longitudinal direction) $[9,14]$. The degree of deviation with respect to the extrusion axis in terms of tilted angle has yet to be confirmed by conducting the pole figure analysis. The similar basal orientation was found out in Mg-CNT composite [31]. The observed basal orientation through texture changes in AZ51 favors the activation of non-basal slip systems [14]. This also provides the assumption of activating more slip systems due to the presence of needle shaped intermetallics in AZ51 contributing to the ductility improvement.

The tensile fracture surfaces of the synthesized materials are shown in Figure 5. All the surfaces revealed dimple like features indicating the degree of material's plasticity which can be correlated to the observed failure strain of more than $10 \%$ (see Table 2). These features can also be related to the presence of second phases which are the sources for the dimple formation thorough particle stimulated void initiation. It has been reported that the dimple formation initiated from the inclusion or intermetallics in AZ31 and the size of dimples depends on the inclusion size [34]. In relation with the formation of fine intermetallics, the fracture surfaces of AZ51 and $A Z 41 / \mathrm{Y}_{2} \mathrm{O}_{3}$ composite revealed a relatively smaller dimple size when compared to that of $A Z 41$ and $A Z 51 / \mathrm{Y}_{2} \mathrm{O}_{3}$ composite.

Figure 5. Representative tensile fractographs in: (a) AZ41; (b) AZ41 $+\mathrm{Y}_{2} \mathrm{O}_{3}$ composite; (c) AZ51 and (d) AZ51 $+\mathrm{Y}_{2} \mathrm{O}_{3}$ composite.

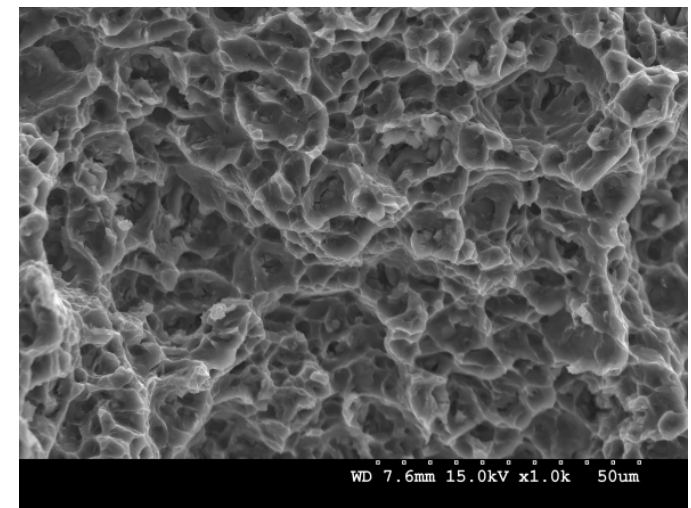

(a)

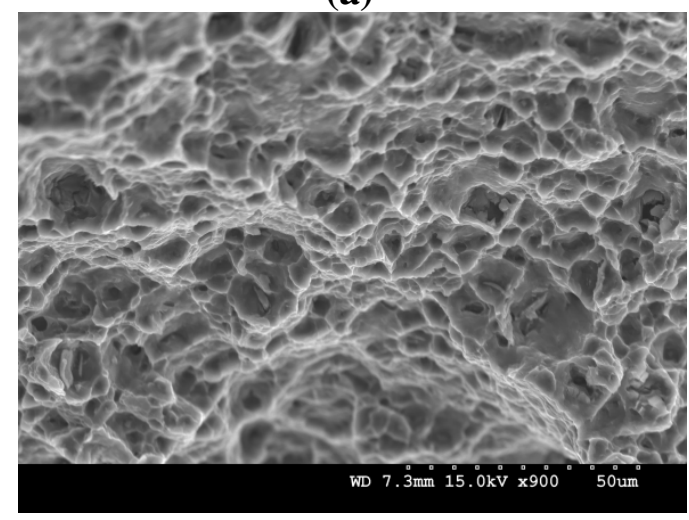

(c)

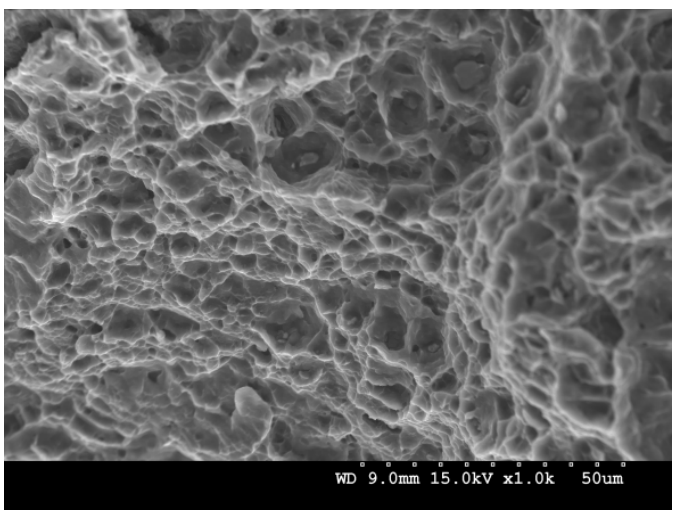

(b)

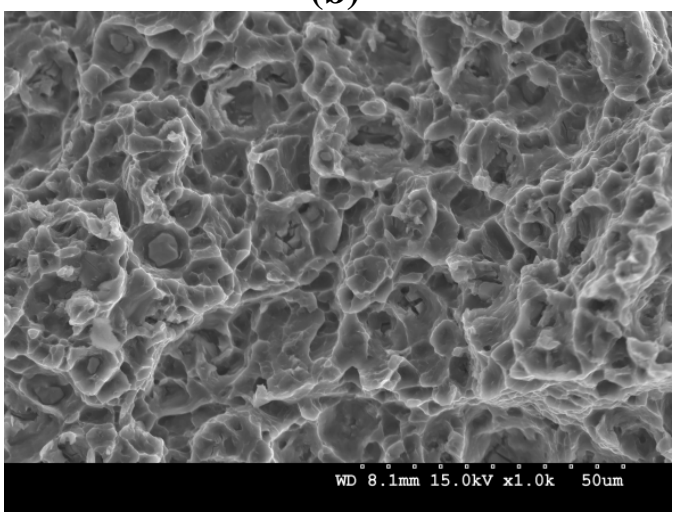

(d)

\subsection{Compressive Properties}

The results of uniaxial compressive testing are shown in Table 3. Except for AZ51, there was no significant difference in $0.2 \%$ compressive yield strength among the synthesized materials. This 
indicates that the variation in neither grain size nor the amount of second phases affects the yield strength variation. A similar phenomenon has been observed in a previous study on the $\mathrm{Mg}$ composites [15]. For magnesium which is highly sensitive to texture, the yielding behavior is commonly controlled by the crystallographic texture. As observed in the XRD pattern of AZ51, the presence of random texture was observed (Figure 4b). The compressive yield strength generally decreases in the materials which exhibit strong basal texture which favors the activation of twinning in the $\{10-12\}<10-11>$ system [35-37]. However, with texture randomization, an increase in compressive yield strength was observed in $\mathrm{Mg} / \mathrm{Y}_{2} \mathrm{O}_{3}$ composite in the related study [38]. The current compressive yield strength improvement in AZ51 is in agreement with the reported compressive yielding variation observed in the $\mathrm{Mg} / \mathrm{Y}_{2} \mathrm{O}_{3}$ composite [38]. On the other hand, a significant improvement in ultimate compressive strength was observed in $A Z 51 / \mathrm{Y}_{2} \mathrm{O}_{3}$ composite when compared to the rest of the synthesized materials (see Table 3 ). The grain refinement and the formation of fine intermetallics and/or reinforcement did not support the compressive strength improvement in AZ51 and $\mathrm{AZ41} / \mathrm{Y}_{2} \mathrm{O}_{3}$ composite. When compared to $\mathrm{AZ51}$, the presence of coarse intermetallics might be the possible reason for compressive strength improvement in $A Z 51 / \mathrm{Y}_{2} \mathrm{O}_{3}$ composite. The compressive failure strain was found to be higher in $\mathrm{AZ41}$ and $\mathrm{AZ51} / \mathrm{Y}_{2} \mathrm{O}_{3}$ composite than that in $\mathrm{AZ51}$ and $\mathrm{AZ41} / \mathrm{Y}_{2} \mathrm{O}_{3}$ composite. Although the yielding in magnesium materials which commonly have strong basal texture is due to twinning, the deformation after yielding (strain hardening region) is reported to be slip dominated deformation especially in the fine grained materials [8]. Barnett et al. [8] showed that slip dominated flow was observed for magnesium alloy with fine grain size and low amount of twinning was found after compression. Similarly, in the present study, the lower compressive failure strain in AZ51 and $A Z 41 / \mathrm{Y}_{2} \mathrm{O}_{3}$ composite can be attributed to the finer grain size with slip dominated flow. For AZ41 and AZ51/ $\mathrm{Y}_{2} \mathrm{O}_{3}$ composite, comparatively coarser grain size (about double in size) could favor more twinning to accommodate higher plastic deformation. In addition, the analysis of fracture surfaces on $\mathrm{AZ41}$ and $\mathrm{AZ51} / \mathrm{Y}_{2} \mathrm{O}_{3}$ composite showed relatively smooth features indicating enhanced plastic deformation (Figure 6a,d) which is in agreement with the observed improved compressive failure strain in the materials (Table 3). In case of AZ51 and $\mathrm{AZ} 41 / \mathrm{Y}_{2} \mathrm{O}_{3}$ composite, comparatively rough surfaces with more fractured edges were observed (Figure 6b,c). This indicates that the presence of closely spaced second phases hindered the plastic continuity showing numerous fracture marks upon failure which reflect the low compressive ductility in the materials (Table 3).

Table 3. Results of room temperature compressive properties.

\begin{tabular}{lccc}
\hline Materials & 0.2\%CYS (MPa) & UCS $(\mathbf{M P a})$ & Failure Strain (\%) \\
\hline $\mathrm{AZ41}$ & $165 \pm 4$ & $501 \pm 8$ & $17 \pm 0.3$ \\
$\mathrm{AZ51}$ & $185 \pm 11$ & $508 \pm 11$ & $15 \pm 1$ \\
$\mathrm{AZ41}+\mathrm{Y}_{2} \mathrm{O}_{3}$ & $160 \pm 13$ & $451 \pm 20$ & $11 \pm 1$ \\
$\mathrm{AZ51}+\mathrm{Y}_{2} \mathrm{O}_{3}$ & $167 \pm 6$ & $564 \pm 12$ & $22 \pm 1$ \\
\hline
\end{tabular}


Figure 6. Representative compressive fractographs in: (a) AZ41; (b) $\mathrm{AZ41}+\mathrm{Y}_{2} \mathrm{O}_{3}$ composite; (c) AZ51 and (d) AZ51 $+\mathrm{Y}_{2} \mathrm{O}_{3}$ composite.

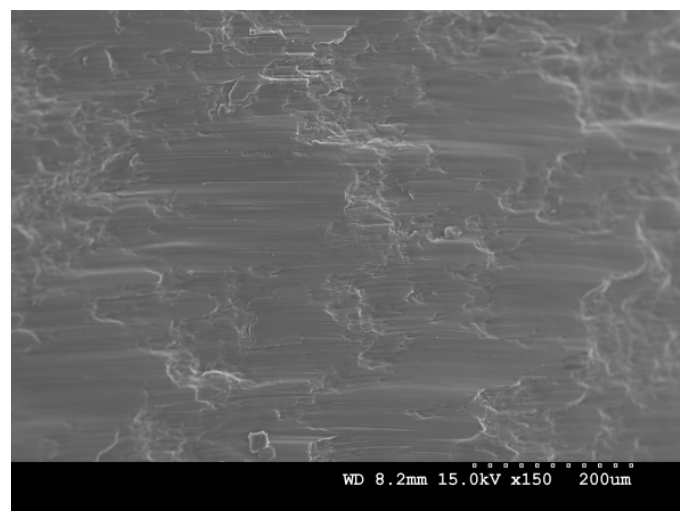

(a)

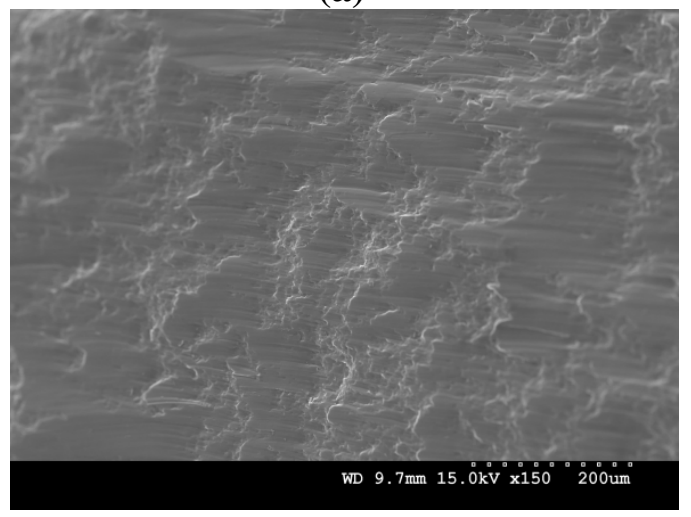

(c)

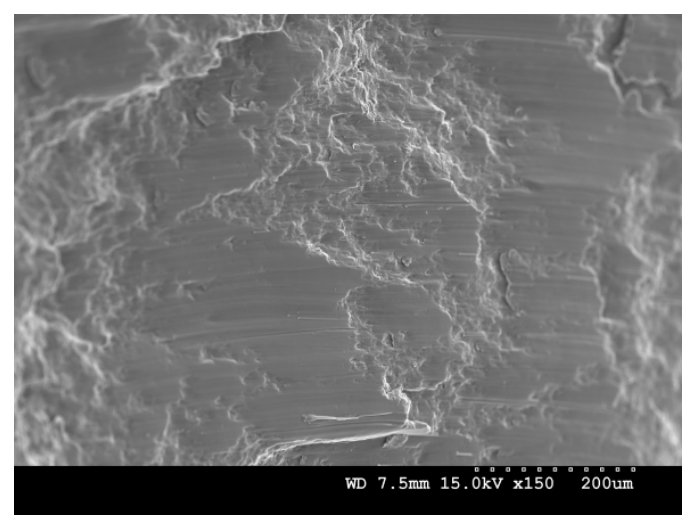

(b)

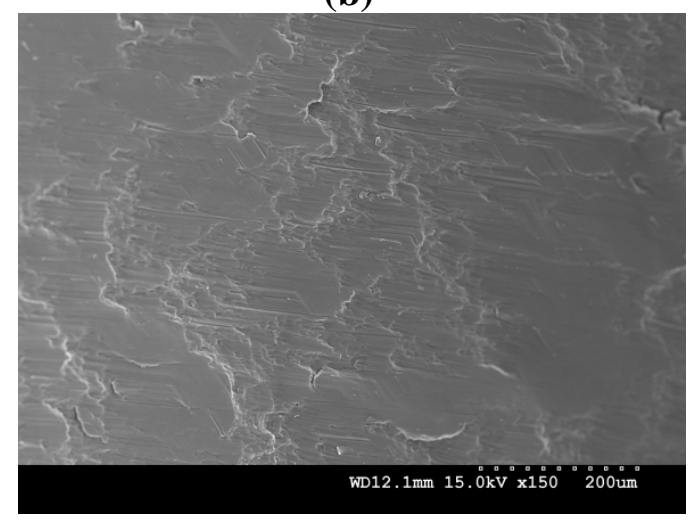

(d)

\section{Materials and Experimental Procedures}

In the present study, the matrix materials used was AZ31 magnesium alloy ingots $(2.9 \% \mathrm{Al}$, $0.8 \% \mathrm{Zn}, 0.6 \% \mathrm{Mn}, 0.0023 \% \mathrm{Fe}, 0.0011 \% \mathrm{Si}, 0.0012 \% \mathrm{Cu}, 0.0004 \% \mathrm{Ni}$ and balance $\mathrm{Mg}$ ). The aluminum lumps (small, irregular blocks) of $99.5 \%$ purity (Alfa Aesar, USA) were used for alloying purpose and yttria $\left(\mathrm{Y}_{2} \mathrm{O}_{3}\right)$ powder of $99.95 \%$ purity with a particulate size range of $30-50 \mathrm{~nm}$ (Inframat Advanced Materials, USA) was used as the ceramic reinforcement phase. $\mathrm{Y}_{2} \mathrm{O}_{3}$, one of the potential oxide ceramics was chosen as reinforcement because of its high thermodynamic stability at elevated temperatures. Moreover, thermal stability of yttria in magnesium suggests minimal reaction between matrix and reinforcement leading to good interfacial integrity [18].

Magnesium alloys (AZ31, AZ41 and AZ51) and composites (AZ41 $+\mathrm{Y}_{2} \mathrm{O}_{3}$ and $\mathrm{AZ51}+\mathrm{Y}_{2} \mathrm{O}_{3}$ ) were synthesized using Disintegrated Melt Deposition (DMD) technique. The detailed description of the processing technique can be found in the previous paper [24]. AZ41 and AZ51 magnesium alloys were fabricated by adding $1 \mathrm{wt} \%$ and $2 \mathrm{wt} \%$ of aluminum into AZ31 alloy. For the synthesis of AZ41 and AZ51 magnesium composites, $0.6 \mathrm{wt} \%$ (0.22 vol.\%) $\mathrm{Y}_{2} \mathrm{O}_{3}$ was added together with $1 \mathrm{wt} \%$ and $2 \mathrm{wt} \%$ of aluminum into AZ31 alloy. The deposited ingots of $40 \mathrm{~mm}$ diameter were machined down to $36 \mathrm{~mm}$ diameter followed by hot extrusion at $350{ }^{\circ} \mathrm{C}$. The machined ingots were coated with colloidal graphite and soaked at $400{ }^{\circ} \mathrm{C}$ for $1 \mathrm{~h}$ prior to extrusion. The extruded rods of $8 \mathrm{~mm}$ in diameter were used for further characterization studies. 
Microstructural characterization studies were conducted to determine grain size, grain morphology, presence and distribution of reinforcements and intermetallics. OLYMPUS metallographic optical microscope, Scion Image Analyzer and HITACHI S-4300 Field Emission Scanning Electron Microscope (FESEM) were used for this purpose. X-ray diffraction analysis was carried out on the polished extruded $\mathrm{Mg}$ and $\mathrm{Mg}$ nanocomposite samples using automated Shimadzu LAB-X XRD-6000 diffractometer.

The mechanical behavior of both monolithic and composite samples was quantified in terms of microhardness, tensile and compressive properties. Microhardness measurements were performed on the polished samples using Shimadzu-HMV automatic digital microhardness tester. The microhardness test was performed using a Vickers indenter under a test load of $25 \mathrm{gf}$ and a dwell time of $15 \mathrm{~s}$ in accordance with the ASTM standard E384-99. Room temperature tensile and compressive tests were performed using an automated MTS 810 servo hydraulic testing machine. The tensile properties of the samples were determined in accordance with procedures outlined in ASTM standard E8M-01. The tensile tests were conducted on round tension test specimens $(5-\mathrm{mm}$ gage diameter and 25-mm gage length). Compression tests were performed according to ASTM E9-89a. Extruded rod of $8 \mathrm{~mm}$ diameter was cut into $8 \mathrm{~mm}$ length samples for compression tests to provide the aspect ratio (1/d) of unity. Samples were tested at a strain rate of $5 \times 10^{-3} \mathrm{~min}^{-1}$ and the compression load was applied parallel to the extrusion direction.

\section{Conclusions}

(1) Microstructure observation revealed the formation of discontinuous $\mathrm{Mg}_{17} \mathrm{Al}_{12}$ intermetallics in both AZ41 and AZ51 alloys. The intermetallics formed are of different morphologies: coarse, blocky intermetallics in AZ41 and combined form of coarse, blocky and fine, needle shaped intermetallics in AZ51. The coarse intermetallics in AZ41 were partially broken down into fine intermetallics due to the presence of $\mathrm{Y}_{2} \mathrm{O}_{3}$ in $\mathrm{AZ} 41 / \mathrm{Y}_{2} \mathrm{O}_{3}$ composite. However, the formation of coarse intermetallics and absence of needle shaped intermetallics were observed in $\mathrm{AZ51} / \mathrm{Y}_{2} \mathrm{O}_{3}$ composite regardless of having added the same amount of $\mathrm{Y}_{2} \mathrm{O}_{3}$ into AZ51.

(2) The microhardness was increased in $A Z 41 / \mathrm{Y}_{2} \mathrm{O}_{3}$ composite, whereas a decrease in microhardness was observed in $\mathrm{AZ51} / \mathrm{Y}_{2} \mathrm{O}_{3}$ composites when compared to that of $\mathrm{AZ41}$ and AZ51. The highest microhardness was observed in $\mathrm{AZ41}+\mathrm{Y}_{2} \mathrm{O}_{3}$ composite among all synthesized materials.

(3) An improvement in both $0.2 \%$ yield strength and ultimate tensile strength was observed in $\mathrm{AZ51}, \mathrm{AZ41} / \mathrm{Y}_{2} \mathrm{O}_{3}$ and $\mathrm{AZ51} / \mathrm{Y}_{2} \mathrm{O}_{3}$ composites through the addition of $\mathrm{Al}$ and/or $\mathrm{Y}_{2} \mathrm{O}_{3}$ into AZ41. The failure strain was increased in AZ51 which is correlated to the formation of needle shaped intermetallics and texture changes. Being the same basal texture, the failure strain remained at a similar level in the rest of the synthesized materials but it was lower than that of AZ51.

(4) Similar compressive yield strength was observed in the synthesized materials except AZ51. The improvement in yield strength particularly in AZ51 was associated with the observed random texture. The compressive failure strain in $\mathrm{AZ41}$ and $\mathrm{AZ51} / \mathrm{Y}_{2} \mathrm{O}_{3}$ composite was found to be higher than that of $\mathrm{AZ} 51$ and $\mathrm{AZ41} / \mathrm{Y}_{2} \mathrm{O}_{3}$ composite. Variation in compressive failure strain was affected by the difference in grain sizes. 


\section{Acknowledgments}

The authors would like to acknowledge the Qatar National Research Fund (QNRF), Qatar (NPRP 08-424-2-171) for supporting this research.

\section{Conflict of Interest}

The authors declare no conflict of interest.

\section{References}

1. Mordike, B.L.; Kainer, K.U. Magnesium Alloys and Their Applications; Werkstoff-Insformations gesellschaft: Frankfu, Germany, 1998.

2. Kainer, K.U. Magnesium Alloys and Technology; WILEY-VCH: Weinheim, Germany, 2003.

3. Polmear, I.J. Magnesium alloys and applications. Mater. Sci. Technol. 1994, 10, 1-16.

4. Friendich, H.; Schumanm, S. Research for a new age of magnesium in the automotive industry. J. Mater. Process. Technol. 2001, 117, 276-281.

5. Mordike, B.L.; Ebert, T. Magnesum: Properties, applications, potential. Mater. Sci. Eng. A 2001, 302, 37-45.

6. Yang, Z.; Li, J.P.; Zhang, J.X.; Lorimer, G.W.; Robson, J. Review on research and development of magnesium alloys. Acta Metall. Sin. 2008, 21, 313-328.

7. Agnew, S.R.; Tome, C.N.; Brown, D.W.; Holden, T.M.; Vogel, S.C. Study of slip mechanisms in a magnesium alloy by neutron diffraction and modelling. Scripta Mater. 2003, 48, 1003-1008.

8. Barnett, M.R.; Keshavarz, Z.; Beer, A.G.; Atwell, D. Influence of grain size on the compressive deformation of wrought Mg-3Al-1Zn. Acta Mater. 2004, 52, 5093-5103.

9. Mukai, T.; Yamanoi, M.; Watanabe, H.; Higashi, K. Ductility enhancement in AZ31 magnesium alloy by controlling its grain structure. Scripta Mater. 2001, 45, 89-94.

10. Chino, Y.; Kimura, K.; Hakamada, M.; Mabuchi, M. Mechanical anisotropy due to twinning in an extruded AZ31 Mg alloy. Mater. Sci. Eng. A 2008, 485, 311-317.

11. Yin, S.M.; Wang, C.H.; Diao, Y.D.; Wu, S.D.; Li, S.X. Influence of grain size and texture on the yield asymmetry of Mg-3Al-1Zn alloy. J. Mater. Sci. Technol. 2011, 27, 29-34.

12. Laser, T.; Hartig, C.; Nurnberg, M.R.; Letzig, D.; Bormann, R. The influence of calcium and cerium mischmetal on the microstructural evolution of $\mathrm{Mg}-3 \mathrm{Al}-1 \mathrm{Zn}$ during extrusion and resulting mechanical properties. Acta Mater. 2008, 56, 2791-2798.

13. Morisada, Y.; Fujii, H.; Nagaoka, T.; Fukusumi, M. MWCNTs/AZ31 surface composites fabricated by friction stir processing. Mater. Sci. Eng. A 2006, 419, 344-348.

14. Nguyen, Q.B.; Gupta, M. Increasing significantly the failure strain and work of fracture of solidification processed AZ31B using nano- $\mathrm{Al}_{2} \mathrm{O}_{3}$ particulates. J. Alloy. Compd. 2008, 459, 244-250.

15. Nguyen, Q.B.; Gupta, M. Enhancing compressive response of AZ31B magnesium alloy using alumina nanoparticulates. Comp. Sci. Technol. 2008, 68, 2185-2192. 
16. Nguyen, Q.B.; Tun, K.S.; Chan, J.; Kwok, R.; Kumar, J.V.M.; Phung, H.T.; Gupta, M. Simultaneous effect of nano- $\mathrm{Al}_{2} \mathrm{O}_{3}$ and micrometre $\mathrm{Cu}$ particulates on microstructure and mechanical properties of magnesium alloy AZ31. Mater. Sci. Technol. 2012, 28, 227-233.

17. Hassan, S.F.; Gupta, M. Development and characterization of ductile $\mathrm{Mg} / \mathrm{Y}_{2} \mathrm{O}_{3}$ nanocomposites. J. Eng. Mat. Technol. 2007, 129, 462-467.

18. Goh, C.S.; Wei, J.; Lee, L.C.; Gupta, M. Properties and deformation behaviour of $\mathrm{Mg}-\mathrm{Y}_{2} \mathrm{O}_{3}$ nanocomposites. Acta Mater. 2007, 55, 5115-5121.

19. Tun, K.S.; Gupta, M. Improving mechanical properties of magnesium using nano-Yttria reinforcement and microwave assisted powder metallurgy method. Comp. Sci. Technol. 2007, 67, 2657-2664.

20. Avedesian, M.M.; Baker, H. ASM Specialty Handbook: Magnesium and Magnesium Alloys; ASM International: Materials Park, OH, USA, 1999.

21. StJohn, D.H.; Qian, M.; Easton, M.A.; Cao, P.; Hildebrand, Z. Grain refinement in Mg alloys. Metall. Mater. Trans. A 2005, 36, 1669-1679.

22. Lee, Y.C.; Dahle, A.K.; StJohn, D.H. The role of solute in grain refinement of magnesium. Metall. Mater. Trans. A 2000, 31, 2895-2906.

23. Song, C.J.; Han, Q.Y.; Zhai, Q.J. Review of grain refinement methods for as-cast microstructure of magnesium alloy. China Foundary 2009, 6, 93-103.

24. Kang, Y.C.; Chan, S.L. Tensile properties of nanometric $\mathrm{Al}_{2} \mathrm{O}_{3}$ particulate-reinforced aluminum matrix composites. Mater. Chem. Phys. 2004, 85, 438-443.

25. Choi, H.; Sun, Y.; Slater, B.P.; Konishi, H.; Li, H. AZ91D/TiB2 nanocomposites fabricated by solidification nanoprocessing. Adv. Eng. Mater. 2012, 14, 291-295.

26. Shanthi, M.; Tun, K.S.; Pandey, R.S.; Gupta, M. Enhancing overall tensile behavior or ductility of AZ91D using nano- $\mathrm{Al}_{2} \mathrm{O}_{3}$ and heat treatment. Met. Mater. 2011, 49, 197-205.

27. Asla, K.M.; Tari, A.; Khomamizadeh, F. The effect of different content of Al, RE and Si element on the microstructure, mechanical and creep properties of Mg-Al alloys. Mater. Sci. Eng. A 2009, 523, 1-6.

28. Suryanarayana, C. Mechanical alloying and milling. Prog. Mater. Sci. 2001, 46, 1-25.

29. Cullity, B.D. Element of X-Ray Diffraction, 2nd ed.; Addison-Wesley: Reading, MA, USA, 1978; p. 414.

30. McDanels, D.C. Analysis of stress-strain, fracture and ductility behavior of aluminum matrix composites containing discontinuous silicon carbide reinforcement. Metall. Trans. A 1985, 16, 1105-1115.

31. Goh, C.S.; Wei, J.; Lee, L.C.; Gupta, M. Ductility improvement and fatigue studies in Mg-CNT nanocomposites. Comp. Sci. Technol. 2008, 68, 1432-1439.

32. Fleck, N.A.; Muller, G.M.; Ashby, M.F.; Hutchinson, J.W. Strain gradient plasticity: Theory and experiment. Acta Metall. Mater. 1994, 42, 475-487.

33. Arsenault, R.J.; Shi, N. Dislocation generation due to differences between the coefficients of thermal expansion. Mater. Sci. Eng. 1986, 81, 175-187.

34. Somekawa, H.; Mukai, T. Effect of texture on fracture toughness in extruded AZ31 magnesium alloy. Scripta Mater. 2005, 53, 541-545. 
35. Jiang, J.; Godfrey, A.; Liu, W.; Liu, Q. Microtexture evolution via deformation twinning and slip during compression of magnesium alloy AZ31. Mater. Sci. Eng. A 2008, 483-484, 576-579.

36. Klimanek, P.; Potzsch, A. Microstructure evolution under compressive plastic deformation of magnesium at different temperatures and strain rates. Mater. Sci. Eng. A 2002, 324, 145-150.

37. Barnett, M.R. Influence of deformation conditions and texture on the high temperature flow stress of magnesium AZ31. J. Light Met. 2001, 1, 167-177.

38. Garces, G.; Rodriguez, M.; Perez, P.; Adeva, P. Effect of volume fraction and particle size on the microstructure and plastic deformation of $\mathrm{Mg}_{-} \mathrm{Y}_{2} \mathrm{O}_{3}$ composites. Mater. Sci. Eng. A 2006, 419, $357-364$.

(C) 2012 by the authors; licensee MDPI, Basel, Switzerland. This article is an open access article distributed under the terms and conditions of the Creative Commons Attribution license (http://creativecommons.org/licenses/by/3.0/). 